\title{
Factors Affecting Adoption of Sustainable Soil Management Practices among Fluted Pumpkin Producers in Ikorodu, Lagos State
}

\author{
Olatomide W. Olowa ${ }^{1}$, Omowumi A. Olowa ${ }^{1}$, Akinkunmi A. Falade ${ }^{1}$ and \\ Ijiyokun, A.O. ${ }^{1}$
}

\begin{abstract}
Proper soil management is germane to sustainable vegetable production. The greatest threat to sustainable agricultural productivity is the declining soil productivity. The reason for this declining soil productivity might not be unconnected with the soil management practices by farmers. This study attempts to isolate factors that are contributing to vegetable farmers' adoption of soil management practices. Primary data were collected from purposively selected 120 fluted pumpkin vegetable farmers, adopting pre-tested semi-structured interview schedule in Ikorodu Local Government Area. This is predicated on the facts that Ikorodu environment seems to be well adapted for fluted pumpkin production as many hectares of land are cultivated to fluted pumpkin by hundreds of small holders. Probit regression model was used to isolate factors affecting the adoption of sustainable soil management practices. Overall, the model predicted $85.76 \%$ of the sample correctly. The findings of the study revealed that number of economically active family members, farmers' education, livestock holding, membership in farmer's group and credit availability were significantly positive while age of farmer negatively affect adoption of sustainable soil management practice. A unit increased in economically active family members, years of education and livestock standard unit would increase the probability of adoption of technology by $21.3,5.8$ and $7.6 \%$ respectively. Likewise, if farmers were made member in the groups and credit made available, the probability of adoption of technology would increase by 46.2 and $46.3 \%$ respectively. But a unit increase in the age of household head would decrease the level of adoption by $1.4 \%$ indicating old aged farmers do not adopt innovative technologies in agriculture.
\end{abstract}

Keywords: Lagos, adoption, probit, sustainable soil management, vegetable, fluted pumpkin

\section{Introduction}

Degradation of land is a reduction in its productivity that may result from loss, breakdown in soil structure, salinization, water logging, nutrient loss, and pollution from toxic substances. Most of these factors are the result of Agricultural activities (ADB, 1995). The Federal Ministry of Agriculture, (1987) defined soil conservation/management as the wise use of land so that its productivity is kept high over a relatively long period of time. According to their definition, soil conservation encompasses three phases namely: Sustaining the fertility of soil and protection from destruction; studying and planning control measures for degraded soil; and actual reclamation of degraded soil. It has been said that the greatest threat to sustaining agricultural productivity in Nigerian farming is the decline in soil productivity. As a result of this, a number of programmes and policies aimed at promoting soil conservation practices have been mounted by Nigerian government. The common soil management practices among vegetable farmers can be classified into two namely indigenous and 
non-indigenous practices. Minimum tillage, bush fallow, zero-tillage, shifting cultivation, ridging across the slope and manure/plant residue management are popular indigenous soil management practices while fertilizer use and crop rotation are non-indigenous soil management practice in Nigeria. The greatest threat to sustaining agricultural productivity in Nigerians farming communities is the declining productivity of soil caused by one, Loss of soil fertility due to removal of top soil by agents of soil erosion due to inappropriate land use practices. Two, Loss of soil structure and porosity due to continuous cultivation and laterisation of top soil. As a result of continuous exposure to sun by anthropogenic agents (man and animals) soil water content are continuously reduced during the process. Three, destruction of natural soil structure due to wrong adoption and use of modern technology (e.g. use of heavy farm machines). The spectacular emergence of the problem of soil erosion (including sheet, wind and coastal erosion) in nearly all parts of Nigeria is an attestation of the inappropriate land use practices in many communities (Federal Ministry of Agric., Water Res. and Rural Development, 1987). As far back as 1977, Olayide and Falusi, had observed that the country is under the threat of massive depletion of her soil due to the increasing occurrence of improper farming and cultivation practices which expose the soil to harsh weather conditions. Over 40 years later, the fertility status of Nigeria's soil resources have continued to decline. Despite several uncoordinated attempts to address the problem of land degradation and soil depletion, fluted pumpkin farmers in the southern part of Nigeria have not been too eager to adopt or invest in soil conservation practices introduced to them. Agbamu (1993) after closely studying the soil management practices adoption behaviour of small farmers in Lagos State concluded that the attitude of most farmers in south western Nigeria towards the adoption of soil conservation practices 'has not been encouraging. With the initiation of commercial vegetable cultivation, there have been increasing trend of chemicals use. Excessive application of chemical fertilizers and pesticides thereby causing toxicity of soil. Also, huge amount of money is being spent for the import of chemical fertilizers and pesticides every year.

In spite of massive subsidy regime in the fertilizer supply, small holders cannot afford the quantum of fertilizers required to meeting soil requirement (Subedi et al., 2001). On the other hand, excessive use of chemicals in agriculture is reducing soil fertility. Almost all the soil in Nigeria has become deficient in organic matter due to poor management practices. To cope with the situation of pesticide hazards and environment deterioration, a case for sustainable soil management practice is made in this paper. Sustainable soil management (SSM) practices are compatible with the capabilities of rural communities and smallholder farmers who generally lack capital to buy synthetic pesticides and inorganic fertilizers. In some situations SSM based growers may be less vulnerable to natural and economic risks than conventional farmers since their systems are usually more diversified (Olson et al., 1982). Also, addition to this Nowadays, various areas in the world have faced water logging and salinity problems, which are intensified by a myriad of factors including use of wastewaters for irrigation, unsuitable cropping pattern, torrential rains and floods, lack of sufficient drainage, uncontrolled drainage, lack of adequate knowledge, wrong management decisions, very poor construction and rehabilitation rates of drainage systems, increase of irrigation systems without paying any attention to their adverse impacts on soil and quality of water resources, etc. (Valipour, 
2014). Under good soil management practice, fluted pumpkin yield as high as 500-1000 $\mathrm{kg} / \mathrm{ha}$ and can also be as high as 3-10t/ha depending on the management system. The seed yield can be up to 1.9t/ha derived from 3000 fruits. Hence the need for sustainable management practice for soil.

Although, there are many agricultural technologies nowadays available for farmers which are eco-friendly and sustainable, their use and sustainable adoption is not known. Farmers are adopting such practices whose profitability, sustainability, and viability are alien to them. Poor extension and adoption rate of improved farming technology have been implicated in Nigerian agriculture development. Thus, the general objective of this study is to find out the level of adoption and the major factors influencing adoption of sustainable soil management practice

Specifically, the study seek to:

(i) find the level of adoption of Sustainable Soil Management practice among fluted pumpkin vegetable farmers.

(ii) identify the major factors influencing the level of adoption of Sustainable Soil Management practice.

(iii) isolate the factors influencing adoption of Sustainable Soil Management practice.

\section{Methodology}

Ikorodu Local government Area (ILGA) is divided into six Local Council Development Areas (LCDAs) namely Ikorodu West, Ikorodu North, Ijede, IgbogboBayeku, Imota and Ikosi-Agbowa. Apart from Ikorodu West with seemingly metropolitan nature, farming activities are carried out extensively in other five LCDAs. Fluted pumpkin farming/production is largely carried out in all the LCDAs but Ijede. All the four LCDAs were covered in the sample survey. Thirty fluted pumpkin farmers were purposively selected in each LCDA. Thus one hundred and twenty farmers were selected. Majority of these $u g u$ farmers were full-time producers who have no non-farm activities.

Primary data was collected using semi-structured interview schedule. The instrument elicited information on age, gender, years of experience in vegetable farming, membership of farmers' group, training received or otherwise and on soil management practices. Information were collated on soil management or conservation practices and subjected to adoption index to calculate the level of Sustainable Soil Management (SSM) practice adoption, following Dongol (2004). Thus farmers were categorised into different levels of adoption such as high adoption, medium adoption, and low adoption, based on the derived adoption index. Probit regression model was applied to determining factors affecting level of adoption of SSM practices in this study. The characteristic feature of probit models is that the effect of independent variables on dependent variables is nonlinear. It is a statistics model which aims to form a relation between probability values and explanatory variables and to ensure that the probability value remains between 0 and 1. In the Probit model, suppose $Y_{i}$ be the binary response of the farmers and take only two possible values; $Y=1$, if farmer's adoption level is more than $84 \%$ and $Y=0$, if less than $84 \%$ (Bhusal, 2012). Suppose $\mathrm{x}$ be the vector of several explanatory variables affecting to the level of adoption and $\beta$, a vector of slope parameters, which measures 
the changes in $\mathrm{x}$ on the probability of the farmers to adopt the practice at higher level. The probability of binary response was defined as follows:

$$
\begin{aligned}
& \text { if } Y_{i}=1 ; \operatorname{Pr}\left(\mathrm{Y}_{i}=1\right) \\
& Y_{i}=0 ; \operatorname{Pr}\left(\mathrm{Y}_{i}=0\right)=1-P
\end{aligned}
$$

Where, $P i=E\left(Y_{i}=1 / X\right)$ represents the conditional mean of $\mathrm{Y}$ given certain values of X.

According to Nagler (2002) probit model constrains the estimated probabilities to be between 0 and 1 and relaxes the constraint that the effect of the independent variables is constant across different predicted values of the dependent variables. This is normally experienced with the Linear Probability Model (LPM). The advantage of probit model is that it includes believable error term distribution as well as realistic probabilities. There were several factors that affect the level of adoption of the practices at the farm level. Decision to adopt at higher level might be influenced by several socioeconomic, demographic, institutional and financial conditions. The aim of the model is to predict the influence of variables (X) on the probability of adoption of sustainable soil management practices ( $\mathrm{Y}$, dependent variables). Accordingly, the probit model estimate the likelihood of farmers adopting SSM practices as a non-linear function of variables. $\operatorname{Pr}(\mathrm{Y}=1)=(\mathrm{X} \beta)$

\subsection{Model specification}

The Probit model as specified in this study to analyze factors affecting farmer's level of adoption of sustainable soil management practices was expressed as follows: $\operatorname{Pr}(>84 \%=1)=\mathrm{f}\left(\mathrm{b}_{0}+\mathrm{b}_{1} \mathrm{X}_{1}+\mathrm{b}_{2} \mathrm{X}_{2}+\mathrm{b}_{3} \mathrm{X}_{3}+\mathrm{b}_{4} \mathrm{X}_{4}+\mathrm{b}_{5} \mathrm{X}_{5}+\mathrm{b}_{6} \mathrm{X}_{6}+\mathrm{b}_{7} \mathrm{X}_{7}+\mathrm{b}_{8} \mathrm{X}_{8}+\mathrm{b}_{9} \mathrm{X}_{9}\right.$ $\left.+\mathrm{b}_{10} \mathrm{X}_{10}+\mathrm{b}_{11} \mathrm{X}_{11}\right)$.

Where, $\operatorname{Pr}(>84 \%)=$ Probability score of adopting SSM practices $\mathrm{b}_{1}, \mathrm{~b}_{2} \ldots \mathrm{b}_{11}=$ Probit coefficient

$\mathrm{b}_{0}=$ Regression coefficient

\begin{tabular}{|c|c|c|c|}
\hline Variable & Type & \multicolumn{2}{|c|}{ Expectedsign } \\
\hline $\begin{array}{l}\text { Dependent variable } \\
\text { Independent variab }\end{array}$ & Dummy & \multicolumn{2}{|c|}{ Farmers scoring more than $84 \%$ in adoption score. 1 if farmer secured score $>84 \% ; 0$ otherwise } \\
\hline & & & + \\
\hline & & & + \\
\hline & Con & & + \\
\hline & Contir & $\mathrm{C}$ & + \\
\hline Gender & $\begin{array}{l}\text { Dummy } \\
\text { Continuous }\end{array}$ & $\begin{array}{l}\text { Gender of the household head } \\
\text { Age of the household head (years) }\end{array}$ & + \\
\hline Training & Dumn & \multicolumn{2}{|c|}{$\begin{array}{r}\text { whether farmers received training from different govermmental and non-govermmental organization. } \\
\qquad 1 \text { if farmers received training; } 0 \text { otherwise + }\end{array}$} \\
\hline $\begin{array}{l}\text { Live } \\
\text { Men }\end{array}$ & $\begin{array}{l}\text { Cont } \\
\text { Dum }\end{array}$ & $\begin{array}{l}\text { Livestock holding } \quad \text { Livestock Standard Unit, LSU } \\
\text { Participation of respondent on SSM farmers group } 1 \text { if yes; } 0 \text { otherwise }\end{array}$ & $\begin{array}{l}+ \\
+\end{array}$ \\
\hline & Dummy & \multicolumn{2}{|l|}{ Whether farmer had access of credit 1 if farmers had access to credit; 0 otherwise +o } \\
\hline
\end{tabular}

Table 1. Description and A Priori Signs of the variables used in the Probit model. 


\section{Results and Discussion}

\subsection{Socio-demographic characteristics of Fluted pumpkin Farmers}

The socio-demographic characteristics of fluted pumpkin vegetable farmers in the study area were summarized in Table 2 . As shown in the table, majority of the fluted pumpkin farmers were male (53.45\%) with average family size of 6.2 . Average age of farmers was 56.2 years. The socio-demographic analysis further showed that $51 \%$ were economically active. $86.2 \%$ of farmers were male-headed indicative of male dominated farming system in the study area. About $63 \%$ were found to be literate with average level of Education (years) of 12. Average land area cultivated was $0.001342 \mathrm{ha}$ and only 0.00318 ha was under irrigation. This imply that majority of the fluted pumpkin farmers were small holders. Moreover, $62 \%$ of the farmers indicated they had received trainings related to sustainable soil management practices facilitated by their group/ union, as majority of them $(85.8 \%)$ belongs to farmers' group/union. The average livestock holding was 9.12 in the study area.

Table 2: Socio-Demographic Characteristics of Fluted Pumpkin Farmers ( $N=120)$

\begin{tabular}{|l|c|c|c|c|}
\hline Characteristics & Frequency & Percentage & Mean & SD \\
\hline Age (Years) & & & 56.2 & 10.31 \\
\hline Household Head & & & & \\
\hline Male-headed & 103 & 86.2 & & \\
\hline Female-Headed & 17 & 13.8 & & \\
\hline Family Size & & & 6.16 & 3.22 \\
\hline Gender & & & & \\
\hline Male & 64 & 53.45 & & \\
\hline Female & 56 & 46.55 & & \\
\hline Educational Level & & & 12.2 & 2.03 \\
\hline Economically Active & 61 & 51 & & \\
\hline Farming related & 16.8 & 7 & & \\
\hline Non-Farm & 223.2 & 93 & & \\
\hline Training & & & & \\
\hline Yes & 74 & 62.2 & & \\
\hline No & 46 & 37.8 & & \\
\hline Membership of Farmers' Group & & & & \\
\hline Yes & 103 & 85.8 & & \\
\hline No & 17 & 14.2 & & \\
\hline Average Livestock Holding & & & 9.12 & 6.7 \\
\hline Average land Cultivated (Ha) & & & 0.001342 & 0.56 \\
\hline & & & & \\
\hline
\end{tabular}

\subsection{Soil Conservation/Management Practices among Fluted Pumpkin Farmers}

Common soil management practices among fluted pumpkin farmers in Ikorodu are described in Table 3. First, zero tillage, in the study area zero tillage is usually carried out when opening up a new site or returning to an old farmland. The farmers clear the land and the plant residue is left to rot or burnt into ashes. As the table shows, none of the farmer practiced it. Two, fertilizer use. Fertilizer use can be used as a soil 
conservation practice if it is applied to enable quick growth and vegetation coverage of the soil, thereby reducing soil erosion. However, most farmers in Ikorodu use fertilizer mainly for the purpose of direct supply of needed nutrients for crops growth and yield improvement and not for strict conservation purposes. To the farmers, it cannot be said to be an indigenous soil conservation method. According to them, the essence of soil management is to increase or maintain crop yield levels in the short term. The use of fertilizer was found to be the most prevalent soil management practice in the study area. According to Table 3, all the farmers used fertilizer mainly for the purpose of direct and quick supply of nutrient to growing fluted pumpkin. Even though the farmers did not deliberately set out to apply fertilizer for soil conservation purposes, it is possible that the resultant rapid growth in vegetation resulting from the application will have conservation effect on the soil. Three, Minimum tillage. In the study area, minimum tillage involves the use of hoes to disturb the soil in the process of constructing of beds/heaps. Minimum tillage ranks well as soil conservation practice with fertilizer use, as all the farmers $(100 \%)$ practiced it. It is actually the most prevalent indigenous method. Their landholdings are rather too small and fragmented for tractor operation. Four, Bush fallowing. This practice involves the abandoning of a cropland for a period of time to revert to bush. Majority (81\%) of them did not practice it. Only about 19 percent, majority of which reside in Ikosi-Agbowa LCDA, a very rural environment practiced it. The practice is not prevalent in the study area because of the scarcity of land. Five, Mulching. Mulching is a tillage system that ensures a maximum retention of crop residues or other vegetative materials on the soil surface. As seen in Table 3, about 31\% of the farmer were engaged in the practice, while majority $(69 \%)$ have given up the practice. Mulching is practiced mainly by yam farmers. The practice is not common among fluted pumpkin farmers. Six, Crop rotation. Crop Rotation is a practice of growing different crops, one at a time, in a definite sequence on the same piece of land. The practice is not a popular soil management technique in the study area as almost all $(99 \%)$ of the farmer were not engaged in the practice. Seven, Manuring/Plant Residue Management. Plant residue management (PRM) involves seeding through the previous crop residue by either burning of residue or incorporation or mulching. Manuring on the other hand is a soil management system of adding refuse from farm animals and plants to the soil in order to supply nutrients required by plaints. Only a small proportion $(5.1 \%)$ of the farmers was engaged in these practices. About 94.9 percent had given up the practices. Eight, Making Ridges/Heap along/across the slope. This is particularly important in land with sloppy terrain to curb excessive water run-off. Ridging or heaping across the slope is well known as a soil conservation method by the farmer. Only about 8.6 percent of the farmers are currently engaged in the practice. The sloppy location of their farmland pre-dispose them to the practice.

Table 3. Soil Conservation/Management Practices among Fluted Pumpkin Farmers (N=120)

\begin{tabular}{|l|c|c|c|c|}
\hline \multirow{2}{*}{ Soil Management Practices } & \multicolumn{2}{|c|}{ Frequency } & \multicolumn{2}{c|}{ Percentage } \\
\cline { 2 - 5 } & Yes & No & Yes & No \\
\hline Zero Tillage & 0 & 120 & 0 & 100 \\
\hline Use of fertilizer & 120 & 0 & 100 & 0 \\
\hline Minimum Tillage & 120 & 0 & 100 & 0 \\
\hline
\end{tabular}




\begin{tabular}{|l|c|c|c|c|}
\hline \multirow{2}{*}{ Soil Management Practices } & \multicolumn{2}{|c|}{ Frequency } & \multicolumn{2}{c|}{ Percentage } \\
\cline { 2 - 5 } & Yes & No & Yes & No \\
\hline Bush fallowing & 23 & 97 & 19 & 81 \\
\hline Mulching & 37 & 83 & 30.8 & 69.2 \\
\hline Crop rotation & 12 & 108 & 1.0 & 99 \\
\hline Manuring/Plant Residue Management & 6 & 114 & 5.1 & 94.9 \\
\hline Making Ridges/Heap along/across the slope & 10 & 110 & 8.6 & 91.4 \\
\hline
\end{tabular}

\subsection{Scale of Soil management Practice/ Adoption}

Table 4 shows the adoption levels of fluted pumpkin farmers when all the soil management practices were bundled together and adoption index was applied following Dongol (2004). As the Table shows, majority of the respondent that is, 44.2 percent had medium level of adoption (exactly $84.5 \%$ level) of sustainable soil management practices, while, a very small proportion $(18 \%)$ was in the high adoption level category; whereas, $37.50 \%$ were at low level. The breakdown analysis shows that majority of high adoption of soil management practice were found Ikorodu-North (30\%) and Igbogbo-Bayeku $(20 \%)$ LCDAs. The implication of the results is that soil management/conservation technique adoption/practice rate is very low, as about $81 \%$ of the farmers could be classified medium or average and below in their practice of soil conservation on aggregate.

Table 4. Scale of Adoption of Sustainable Soil Management Practices By Respondents

\begin{tabular}{llcccc}
\hline Level of Adoption & \multicolumn{4}{c}{ Local Council Development Area } & Total \\
\cline { 2 - 6 } & Imota & Ikosi-Agbowa & Ikorodu-North & Igbogbo-Bayeku & \\
\hline$<84.5 \%$ (Low) & $12(40)$ & $11(36)$ & $08(26)$ & $14(46)$ & $45(37.5)$ \\
$=84.5 \%$ (Medium) & $14(46)$ & $16(53)$ & $13(43)$ & $10(33)$ & $53(44.2)$ \\
$>84.5 \%$ (High) & $04(13)$ & $03(10)$ & $09(30)$ & $06(20)$ & $22(18.3)$ \\
Total & 30 & 30 & 30 & 30 & $120(100)$ \\
\hline
\end{tabular}

Figures in Parenthesis are Percentages. Average level of Adoption $=84.5 \%$

\subsection{Probit Regression Analysis}

The results of the Probit regression analysis are shown in Table 5. The adoption level of the farmers in the study area was categorized into binary response by the adoption level of more than $84.5 \%=1$ and 0 otherwise. The extent to which the probit regression analysis modeled independent variables used in prediction correctly predicted the dependent variable. Overall, the model predicted 85.76 per cent of the sample correctly. Thus the model may be said to be consistent and meaningful. The Wald test $\left(\mathrm{LR} \mathrm{chi}^{2}\right.$ ) for the model indicated that, the model had good explanatory power at $1 \%$ level. The Pseudo $\mathrm{R}^{2}$ was 0.777 . For robust interpretation of the model, marginal effects were derived from the regression coefficients, calculated from partial derivatives as a marginal probability. The outcome is shown in Table 5. Probit regression analysis showed six variables were statistically significant for the level of adoption and they were; ECONOMICALLY ACTIVE FAMILY MEMBERS, EDUCATION, AGE, LIVESTOCK HOLDING, MEMBERSHIP AND CREDIT. Five other variables namely experience, occupation, training and gender were statistically non-significant and associated positively with adoption while farm size was negatively correlated (Table 5). 
The study revealed that, number of economically active family members was positively significant $(\mathrm{P}<0.05)$ and holding other factors constant, a unit increase in the number of economically active family members would increase probability of level of adoption by $21.3 \%$. This might be due to the availability of the more labor force in the agricultural activities. Teklewold et al. (2006) reported that higher size of the household reduces labour constraints and influence the adoption of new technology positively.

Table 5. Factors Affecting the Level of Adoption of Sustainable Soil Management Practices in the Study Area

\begin{tabular}{|c|c|c|c|c|c|}
\hline Variable & Coefficients & $P>|z|$ & \begin{tabular}{|c|}
$\begin{array}{c}\text { Standard } \\
\text { error }\end{array}$ \\
\end{tabular} & $\mathrm{dy} / \mathrm{dx} \mathrm{x}^{\mathrm{b}}$ & S.E $E^{b}$ \\
\hline $\begin{array}{l}\text { Economically active } \\
\text { members(No.) }\end{array}$ & $0.950 * *$ & 0.014 & 0.385 & 0.213 & 0.094 \\
\hline Education (Years) & $0.257 * * *$ & 0.008 & 0.097 & 0.058 & 0.029 \\
\hline Farm size $(\mathrm{Ha})$ & 0.003 & 0.935 & 0.042 & -0.001 & 0.009 \\
\hline Experience (Years) & 0.121 & 0.577 & 0.217 & 0.027 & 0.051 \\
\hline Gender (Dummy) & 0.147 & 0.692 & 0.692 & 0.033 & 0.158 \\
\hline Age of HH (Years) & $-0.653^{* *}$ & 0.027 & 0.029 & -0.014 & 0.006 \\
\hline Training (Dummy) & 1.013 & 0.088 & 0.594 & 0.272 & 0.196 \\
\hline Livestock holding (LSU) & $0.340^{* *}$ & 0.034 & 0.164 & 0.076 & 0.024 \\
\hline Membership (Dummy) & $1.918^{* * *}$ & 0.002 & 0.624 & 0.462 & 0.164 \\
\hline Credit availability (Dummy) & $1.637 * *$ & 0.011 & 0.644 & 0.463 & 0.207 \\
\hline Occupation (Dummy) & 0.078 & 0.914 & 0.724 & 0.018 & 0.172 \\
\hline Constant & -6.121 & 0.008 & 2.318 & & \\
\hline \multicolumn{6}{|l|}{\begin{tabular}{|l|} 
Summary statistics \\
\end{tabular}} \\
\hline Number of observation(N) & 120 & & & & \\
\hline Log likelihood & -18.248 & & & & \\
\hline LR chi2(10) & $127.15^{* * *}$ & $\begin{array}{c}\text { Prob }>\text { chi2 }= \\
0.000)\end{array}$ & & & \\
\hline Prob>chi2 & 0.000 & & & & \\
\hline Pseudo R2 & 0.777 & & & & \\
\hline $\begin{array}{l}\text { Cases predicted correctly } \\
(\%)\end{array}$ & 85.76 & & & & \\
\hline Goodness of fit test & $\begin{array}{c}\text { Pearson chi2 }(107)= \\
76.85 .\end{array}$ & $\begin{array}{c}\text { Prob }>\text { chi2 }= \\
0.9877\end{array}$ & & & \\
\hline
\end{tabular}

*** Significant at $\mathrm{P}=0.01$; ** significant at $\mathrm{P}=0.05$. ${ }^{\mathrm{b}}$ Marginal change in probability (marginal effects after Probit) evaluated at the sample means.

Higher education level of household head gives the ability to interpret and respond to new information much faster than their counterparts with lower education (Feder et al., 1985). The coefficient of level of Education was positive and highly significant $(\mathrm{P}<0.01)$. One year increase in Education of farmers would increase the level of adoption by $5.8 \%$. This finding is in consonance with the report of Kattel (2009). Age of farmer was negatively significant $(\mathrm{P}<0.05)$. The marginal effect showed a unit increase in the age would decrease the adoption level by 1.4 percent. Similar study by Ghimire and Kafle (2014) showed that age factor negatively affected the adoption of integrated pest management practices in Nepal. This finding is also in tandem with Mussei et al., (2001) 
and Hussain et al. (2011) where they reported that older farmers do not adopt the innovative technologies like IPM; but contrasted sharply with Chebil et al., (2007) who reported otherwise. Livestock holding was positively significant $(\mathrm{P}<0.05)$ and a unit increase in the Livestock holding would increase the adoption level of Soil Management practices by $7.6 \%$. Similar finding was reported by Kudi et al. (2011) which contrasted the findings by Dhital (2010). Coefficient of Membership of Farmers' group was positive and highly significant $(\mathrm{P}<0.01)$, and if farmers participated in a group related with sustainable soil management practices would increase the probability of adoption level by $46.2 \%$. This might not be unconnected with the facts that, farmers derive improved capacity through their involvement in groups/union activities. Nchinda et al. (2010) reported similar findings. Credit Availability was positively significant $(\mathrm{P}<0.05)$ indicating that if farmers were provided credit facility, adoption of Sustainable Soil Management practice would increase, and at the margin by 46.3\%. Tizale (2007), Ghimire B. Dhakal S.C., Sharma S. and Poudel S. (2015) also opined that there is a positive relationship between the intensity of use of various technologies and the availability of credit.

\section{Conclusion and Recommendations}

The study revealed that the fluted pumpkin farmers were aware of different soil management practices and that adoption of any practice depend on a number of factors which affect the adoption process significantly. The study explore the disposition of fluted pumpkin farmers to common soil management practices. The most common practice was found to be fertilizer use (which is a non-indigenous short-term fertility maintenance practice) and minimum tillage (indigenous short/ medium term erosion control practice); bush fallow (indigenous short/medium term fertility maintenance practice); and zero tillage (indigenous short/medium term erosion control practice) were not popular among the farmers. Other fairly prominent practices include mulching (indigenous short-term erosion control practice). The implication of these findings is that the soil conservation practices that foster long term sustainability goals of soil management such as bush-fallow, crop rotation, manure/plant residue management, and green manuring, are not currently popular among the farmers in the study area. Probit regression result suggested that SSM practices could be well extended only after addressing the different socioeconomic problems of the farmers. Economically active family members, Education of farmers, Age of farmers, Livestock holding, Membership of Farmers' group and availability of Credit to farmers were found as most significant factors affecting adoption of SSM practice in the study area. Based on the fore-going, the following recommendations are proposed. One, Technologies, trainings and credit should be provided to farmers especially as the findings of this study showed that economically active members and availability of credit affects adoption of SSM. This is necessary to protect farmer from dissipated energy over declining production due to soil declining productivity. Two, Adoption of SSM was significantly increased with increase in years of education of farmers. Thus, Government and farmers' group should heighten education and training programmes through extension visit, demonstrations, seminars and workshop etc. for farmers to enhance SSM understanding, practice and dissemination. Three, Farmer's group activities should be encouraged by channeling all 
agricultural support programmes and facilities through them. The group should be saddled with the responsibility of educating their members on the dangers of excessive reliance on the use of inorganic fertilizers, as well as, the benefits of substituting other soil nutrient-replenishing practices which are more long-term conservation oriented.

\section{References}

African Development Bank (ADB) (1995) Country Environmental Profile: Sierra Leone. Environmental and Social Policy working Paper series No.17. Pp. 50.

Agbamu, J. U. (1993) "Analysis of farmers' Characteristics Associated with Adoption of Soil Management Innovation in lkorodu Local Government Area of Lagos State. The Nigerian Journal of Rural Extension and developmentvol.1 Nos. 2 \&3.

Bhusal D.R (2012). Impact of cattle urine use technology in farm income of the vegetable growers of Dhading district, Nepal. M.Sc. Agriculture Economics Thesis. Institute of Agriculture and Animal Science (IAAS). Rampur, Chitwan Nepal.

Chebil A and Nasr H, Zaibet L (2007). Farmer's willingness to adopt salttolerant forage in south- eastern of Tunisia In: Adding value to the Agro-Food Supply Chain in the Future Euromediterranean Space. Mediterranean Conference of Agro-Food Social Scientists.

Dhital PR (2010). Factors affecting adoption of recommended technology of cauliflower production in Kavre district of Nepal. M.Sc.Agriculture Extension and Rural Sociology Thesis. Institute of Agriculture and Animal Science (IAAS). Rampur, Chitwan Nepal.

Dongol BBS (2004). Extension Education.1st Ed. Dongol Printers 283 p.

Federal Ministry of Agriculture, Water Resource and Rural Development (1987). Soil Conservation Techniques for Small Scale Farming. Prepared by Department of Agricultural Land Resources, for the occasion of world Food Day, 16th October, 1997

Feder G, Just R.E and Zilberman D (1985). Adoption of agricultural innovations in developing countries: A survey. Economic Development and Cultural Change 33(2):255-298.

Ghimire B, Kafle N (2014). Integrated pest management practices and its adoption determinants among apple farmers in Mustang, Nepal. Scholars Journal of Agriculture and Veterinary Sciences 1(2):83-89.

Ghimire B. Dhakal S.C., Sharma S. and Poudel S. (2015). Factors affecting adoption of sustainable soil management practices among vegetable producers in Dhading, Nepal. Vol. 13(44), pp. 2510-2515.

Hattam C (2006). Adopting organic agriculture: An investigation using the theory of planned behaviour. Poster paper prepared for presentation, International Association of Agriculture Economics Conference, Gold Coast, Australia.

Hussain M, Zia S, Saboor A (2011). The adoption of integrated pest management (IPM) technologies by cotton growers in the Punjab. Soil and Environment 30(1):74-77.

Kattel RR (2009). The impact of coffee production on Nepali smallholders in the value chain. Institute of Environmental Economics and World Trade, Leibniz Universitate. Hannover, Germany. Kudi T.M, Bolaji M, Akinola M.O and Nasa I.D.H (2011). Analysis of adoption of improved maize varieties among farmers in Kwara State, Nigeria. International Journal of Peace and Development Studies 1(3):8-12.

Mussei A, Mwanga J, Verkujil H, Mongi R, Elanga A (2001). Adoption of improved wheat Technologies by small scale farmers in Mbeya District, Southern Highlands, Tanzania. Mexico, D. F.: International Maize and Wheat Improvement Centre (CIMMYT) and the United Republic of Tanzania.

Nagler J (2002). Interpreting probit analysis. New York University. Available at http://www.nyu.edu/classes/nagler/quant2/notes/probit1.pdf.(Accessed on 20/01/2015).

Nchinda V.P, Ambe T.E, Holvoet N, Leke W, Che M.A, Nkwate S.P and Ngassam S.B (2010). Factors influencing the adoption intensity of improved yam (Dioscorea spp.) seed technology in the western highlands and high guinea savannah zones of Cameroon. Journal of Applied Biological Sciences 36:2389-2402.

Olayide, S. 0. and Falusi, A. O (1977): "Economic of Soil Conservation and Erosion Control Practices in Nigeria" in Soil Conservation and management in the Humid Tropics. Eds. D. J. Green land and R. Lai and Published by John Wesley and Sons, New York. 
Olson KD, Langley J, Heady EO (1982). Widespread Adoption of Organic Farming Practices: Estimated Impacts on U.S. Journal of Soil and Water Conservation 37(1):41-45.

Pandey ND (1995). The impacts of the farmers' practices on soil fertility management: A case study in Dhading Besi area, Middle Mountain Region, Nepal. AIT Thesis No: AE-95-44. Asian Institute of Technology, Bangkok Thailand pp. 47-59.

Shrestha PP, Koirala P, Thakur AS (2010). Knowledge practice and use of pesticides among commercial vegetable growers of Dhading district, Nepal. Journal of Agriculture and Environment 11:20-25.

Subedi K.D, Jaisi S, Subedi T.B, Mandal S and Dhital B.K (2001). Gothemaltatha compost mal bewasthapan talim pustika. Sustainable soil Management Programme. SSMP, Bakhundol, Lalitpur, Kathmandu, Nepal 92 p.

Teklewold H, Dadi L, Yami A and Dana N (2006). Determinants of adoption of poultry technology: a double hurdle approach. Livestock Research for Rural Development 18:3.

Tizale CY (2007). The dynamics of soil degradation and incentives for optimal management in the Central Highlands of Ethiopia. Ph.D.Thesis, Department of Agricultural Economics, Extension and Rural Development, Faculty of Natural and Agricultural Sciences, University of Pretoria.

Tripathi BP (2002). Review of acid soil and its management in Nepal. In: Proceedings of the Third National Conference on Science and Technology. Nepal Academy of Science and Technology. Lalitpur, Kathmandu, Nepal.

Valipour M (2014) Drainage, waterlogging, and salinity, Archives of Agronomy and Soil Science 60(12):1625-1640. 